\title{
Medico-Legal Issues Related to Hip and Knee Arthroplasty: A Literature Review Including the Indian Scenario
}

\author{
Satvik Pai ${ }^{1}$ D
}

Received: 29 January 2021 / Accepted: 22 March 2021 / Published online: 30 March 2021

(C) Indian Orthopaedics Association 2021

\begin{abstract}
Total hip arthroplasty (THA) and total knee arthroplasty (TKA) are commonly performed surgeries worldwide. The number of joint replacement surgeries being performed has increased considerably over the past two decades, but it has also seen an increase in litigation associated with it. The purpose of our study was to review and consolidate literature regarding medico-legal issues pertaining to THA and TKA cases. We looked at the causes of litigation, medico legal aspects of pre-operative requirements, optimisation of medical condition, indications and contraindications for arthroplasty, informed consent, implants, mixing of components from different manufacturers and post-operative rehabilitation. We also wanted to analyse available literature and legal proceedings regarding these cases in India specifically.
\end{abstract}

Keywords Medico-legal $\cdot$ Litigation $\cdot$ Arthroplasty $\cdot$ Joint replacement $\cdot$ Lawsuits

\section{Introduction}

Total hip arthroplasty (THA) and total knee arthroplasty (TKA) are commonly performed surgeries worldwide. The number of joint replacement surgeries being performed has increased considerably over the past two decades, but it has also seen an increase in litigation associated with it [1]. In fact orthopaedic adult reconstruction subspecialists are sued for alleged medical malpractice at a rate over twice that of the physician population as a whole [2]. A survey of the American Association of Hip and Knee Surgeons found that $78 \%$ of responding surgeons had been named as a defendant in at least one lawsuit alleging medical malpractice [3]. The purpose of our study was to review and consolidate literature regarding medico-legal issues pertaining to THA and TKA cases. With respect to THA, TKA cases we looked at the causes of litigation, medico-legal aspects of pre-operative requirements, optimization of medical condition, indications and contraindications for arthroplasty, informed consent, implants, mixing of components from different manufacturers and post-operative rehabilitation. We also wanted to

Satvik Pai

satvik.pai@gmail.com

1 Department of Orthopaedic Surgery, Sri Ramachandra Medical College and Research Institute, Ramachandra Nagar, Porur, Chennai, Tamil Nadu 600116, India analyse available literature and legal proceedings regarding these cases in India specifically.

\section{Materials and Methods}

An extensive literature search was conducted to identify studies pertaining to medico-legal issues in relation to total hip arthroplasty (THA) and total knee arthroplasty (TKA). The electronic databases of PubMed and Cochrane Library were explored using the following search terms and Boolean operators: 'medico-legal' OR 'lawsuit' OR 'malpractice' OR 'litigation' AND 'total hip arthroplasty' OR 'total knee arthroplasty' OR 'total hip replacement' OR 'total knee replacement' OR 'THA' OR 'TKA'. No restriction in publication date was applied. Manuscript language was restricted to English. In addition, a comprehensive search of reference lists of all identified articles was conducted to find additional studies. Information about specific medico-legal proceedings involving THA/TKA cases in Indian legal courts, state and national consumer dispute redressal forums, and state medical councils were obtained from different books having compendium of medico-legal judgements. 


\section{Causes for Litigation}

It is important to know the causes of litigation and common allegations in malpractice lawsuits involving hip and knee arthroplasty, so that measures can be taken to prevent such complications occurring and the orthopaedic surgeon can be better prepared in the event of such complications happening. Patterson et al. [4] analysed 115 malpractice claims filed for alleged neglectful primary and revision THA surgeries. They found that in primary cases, nerve injury ("foot drop") was the most frequent allegation with 27 claims. Negligent surgery causing dislocation was alleged in 18 and leg length discrepancy in 14. Medical complications were also reported, including three thromboembolic events and six deaths. In revision cases, dislocation and infection were the most common source of suits. The data pertaining to causes of litigation following THA in various studies is represented in Table 1. Patterson et al. [5] also studied the malpractice claims filed for alleged neglectful primary and revision TKA surgeries.
The analysed 69 primary and eight revision TKAs which were involved in malpractice lawsuits and found that the most frequent factor leading to lawsuits for primary TKA was chronic pain or dissatisfaction in 12 cases, followed by nerve palsy in eight, postoperative in-hospital falls in five, and deep vein thrombosis or pulmonary embolism in three. Medical complications included acute respiratory distress syndrome, cardiac arrest, and decubitus ulcers. Contracture was most common after revision TKA (three of eight cases). They concluded that pre-operative counselling regarding the risks of incomplete pain relief could reduce substantially the number of suits relating to primary TKAs. The data pertaining to causes of litigation following TKA in various studies is represented in Table 2.

Bokshan et al. [6] analysed 213 lawsuits pertaining to THA/ TKAs and found that $15.0 \%$ of cases ended in settlement, $29.6 \%$ ended in a verdict in favour of the patient. The average payment for cases lost in court was significantly larger than cases that ended in settlement. They noted that while complications such as "pain and weakness" are less likely to result in favourable litigation for patients, the presence of an objective
Table 1 Findings on causes of lawsuits following THA in various studies

\begin{tabular}{|c|c|c|c|}
\hline Study & $\begin{array}{l}\text { Number of patients/ } \\
\text { lawsuits }\end{array}$ & Cause of litigation & No. of cases $(\%)$ \\
\hline Patterson et al. [4] & 115 & $\begin{array}{l}\text { Foot drop } \\
\text { Dislocation } \\
\text { Medical Complications } \\
\text { Limb length Discrepancy }\end{array}$ & $\begin{array}{l}27(23.4 \%) \\
18(15.6 \%) \\
17(14.78 \%) \\
14(12.17 \%)\end{array}$ \\
\hline Bokshan et al. [6] & 119 & $\begin{array}{l}\text { Nerve injury } \\
\text { Limb length discrepancy } \\
\text { Pain } \\
\text { Periprosthetic fracture }\end{array}$ & $\begin{array}{l}29(24.3 \%) \\
15(12.6 \%) \\
13(10.9 \%) \\
9(7.5 \%)\end{array}$ \\
\hline Novi et al. [7] & 40 & $\begin{array}{l}\text { Nerve injury } \\
\text { Implant loosening } \\
\text { Dislocation } \\
\text { Metallosis }\end{array}$ & $\begin{array}{l}15(37 \%) \\
8(20 \%) \\
5(12 \%) \\
4(10 \%)\end{array}$ \\
\hline Kheir et al. [8] & 34 & $\begin{array}{l}\text { Nerve injury } \\
\text { Periprosthetic fracture } \\
\text { Chronic pain } \\
\text { Foreign body retention }\end{array}$ & $\begin{array}{l}6(17.6 \%) \\
5(14.7 \%) \\
4(11.8 \%) \\
4(11.8 \%)\end{array}$ \\
\hline Samuel et al. [9] & 65 & $\begin{array}{l}\text { Nerve injury } \\
\text { Limb length discrepancy } \\
\text { Dislocation } \\
\text { Perioperative fracture }\end{array}$ & $\begin{array}{l}25(38.4 \%) \\
17(26.1 \%) \\
8(12.3 \%) \\
7(10.7 \%)\end{array}$ \\
\hline McWilliams et al. [1] & 1004 & $\begin{array}{l}\text { Neurological deficit } \\
\text { Technical error } \\
\text { Infection } \\
\text { Limb length discrepancy }\end{array}$ & $\begin{array}{l}159(13.8 \%) \\
138(11.9 \%) \\
133(11.5 \%) \\
100(8.7 \%)\end{array}$ \\
\hline Bhutta et al. [10] & 352 & $\begin{array}{l}\text { Nerve injury } \\
\text { Technical error } \\
\text { Chronic pain } \\
\text { Limb length discrepancy }\end{array}$ & $\begin{array}{l}69(19.6 \%) \\
50(14.2 \%) \\
48(13.6) \\
41(11.6 \%)\end{array}$ \\
\hline Zengerink et al. [11] & 515 & $\begin{array}{l}\text { Nerve damage } \\
\text { Limb length discrepancy } \\
\text { Dislocation/instability } \\
\text { Technical error }\end{array}$ & $\begin{array}{l}101(19.6 \%) \\
45(8.7 \%) \\
28(5.4 \%) \\
22(4.2 \%)\end{array}$ \\
\hline
\end{tabular}


Table 2 Findings on causes of lawsuits following TKA in various studies

\begin{tabular}{|c|c|c|c|}
\hline Study & $\begin{array}{l}\text { Number of patients/ } \\
\text { lawsuits }\end{array}$ & Cause of litigation & No. of cases (\%) \\
\hline Patterson et al. [5] & 77 & $\begin{array}{l}\text { Chronic pain } \\
\text { Nerve palsy } \\
\text { In-hospital falls } \\
\text { DVT/PE }\end{array}$ & $\begin{array}{l}12(15.5 \%) \\
8(10.3 \%) \\
5(6.4 \%) \\
3(3.8 \%)\end{array}$ \\
\hline Bokshan et al. [6] & 94 & $\begin{array}{l}\text { Pain } \\
\text { Post-operative fall } \\
\text { Hypoxic brain injury } \\
\text { Vascular injury }\end{array}$ & $\begin{array}{l}17(18 \%) \\
9(9.5 \%) \\
7(7.7 \%) \\
6(6.3 \%)\end{array}$ \\
\hline Gibon et al. [12] & 107 & $\begin{array}{l}\text { Infection } \\
\text { Unsatisfactory result } \\
\text { Neurological deficit } \\
\text { Fatality }\end{array}$ & $\begin{array}{l}44(41.1 \%) \\
17(15.8 \%) \\
17(15.8 \%) \\
14(15.8 \%)\end{array}$ \\
\hline Kheir et al. [8] & 49 & $\begin{array}{l}\text { Infection } \\
\text { Chronic pain } \\
\text { Vascular injury } \\
\text { Dislocation }\end{array}$ & $\begin{array}{l}21(42.9 \%) \\
5(10.2 \%) \\
4(8.2 \%) \\
2(4.1 \%)\end{array}$ \\
\hline Samuel et al. [9] & 83 & $\begin{array}{l}\text { Infection } \\
\text { Malalignment } \\
\text { Chronic pain } \\
\text { Death }\end{array}$ & $\begin{array}{l}27(32.5 \%) \\
11(13.2 \%) \\
11(13.2 \%) \\
11(13.2 \%)\end{array}$ \\
\hline McWilliams et al. [1] & 523 & $\begin{array}{l}\text { Infection } \\
\text { Technical error } \\
\text { Post-operative care } \\
\text { Pain }\end{array}$ & $\begin{array}{l}95(16.7 \%) \\
63(11.1 \%) \\
51(8.9 \%) \\
50(8.8 \%)\end{array}$ \\
\hline Bhutta et al. [10] & 246 & $\begin{array}{l}\text { Chronic pain } \\
\text { Technical error } \\
\text { Infection } \\
\text { Post-operative care }\end{array}$ & $\begin{array}{l}58(23.5 \%) \\
57(23.1 \%) \\
44(17.8 \%) \\
43(17.4 \%)\end{array}$ \\
\hline
\end{tabular}

technical complication or nerve injury was associated with an increased risk for a physician loss and a higher payment. Jarvelin et al. [13] analysed factors predisposing to claims and compensations for patient injuries following total hip and knee arthroplasty. They found that patients over 65 years of age were less likely to file a claim than patients under the age of 65 years, patients with increased comorbidity were more likely to file a claim. Following THA, male sex and cemented prosthesis reduced the odds of a claim. Following TKA, a volume of over 300 operations reduced the probability of compensation for certain injury types. Thus they suggested that centralisation of TKA to hospitals with higher volume may reduce the rate of compensable patient injuries. Novi et al. [7] analysed 40 lawsuits pertaining to THA and found that some complications such as nerve injuries and infection are almost always considered directly dependent on physician's errors, and especially in these cases, hospitals try to settle the claim out of court. They suggest that possible strategies to reduce malpractice claims are diligent execution of the surgical procedure and of a proper postoperative management, the correct compilation of a procedure-specific informed consent and adequate doctor-patient communication to provide the necessary explanations, possible risks and realistic expectations. Gibon et al. [12] analysed 107 lawsuits pertaining to TKA and found that frequent complications are not those which raise most of the claims. Patients sue the surgeon when the outcome of the surgery is different from what they were expecting. They also noted that in court judgements or proceeding it is often stated that delay in diagnosis or treatment of a complication involves the personal responsibility of the surgeon. Therefore, the best practice in handling complications or errors in knee arthroplasty is to quickly recognise and to treat them properly as well as to provide the patient comprehensible information. Chen et al. [14] analysed 298 lawsuits following TKA and found that litigation success rates for TKA were higher when involving a technical error such as malalignment, as compared to events less under the surgeon's control such as infection or venous thromboembolism. The number of incorrect prosthesis/ prosthesis size claims was concerning. They suggest that these may be addressed with strict use of pre-operative templating, the WHO Surgical Safety checklist and repeat intra-operative checking of the implant. Mcgrory et al. [2] analysed the relationship between surgeon demographics and malpractice lawsuits for joint reconstruction surgeons. They found that the overall risk of a malpractice claim is related to years spent in practice. After 30 years in an adult reconstruction practice, the cumulative rate of being sued at least once is over $90 \%$. They were unable to identify any relationship between the type, size, 
or location of practice, fellowship training, or surgery volume and the risk of an adult reconstruction surgeon being named as a defendant in a malpractice suit.

\section{Indications and Contraindications for THA/ TKA}

There are various indications for THA/TKA in patients with osteoarthritis of the joint, rheumatoid arthritis, intra articular fractures which cannot be reconstructed by internal fixation, destruction of joint by infection or malignancy, avascular necrosis of femoral head, among others. The decision of arthroplasty is usually taken after trial of non-surgical management or when other surgical procedures are deemed insufficient. The legal importance of the indication for arthroplasty arises when a patient claims that arthroplasty was not indicated in the patient or not appropriate for the patient. It is also important to discuss the indication for the arthroplasty with the patients to ensure that they understand the primary reason why the procedure is being done, so as to avoid unrealistic expectations of post-surgical outcomes. Gademan et al. [15] performed a systematic review of the indication criteria for THA, TKA in literature and found that they could be divided into four main domains of pain, function, radiological changes and failed conservative therapy. However, they noted that specific cut-off values or ranges in the domains were lacking and the level of evidence was low. Cross et al. [16] studied the consensus among orthopaedic surgeons and found that there no agreement regarding the indications for total knee arthroplasty. They also studied the agreement between orthopaedic surgeons, rheumatologists, and primary care providers and found that 'pain not responsive to drug therapy' was the only indication for TKA which had sufficient agreement. 'Major psychiatric disorder, including dementia' was the only contraindication for TKA which had consensus. This we believe, increases the importance of documentation of indication for arthroplasty by the orthopaedic surgeon. In the case of KS Sridhar vs Rajkumar (I(07)CPJ 362) [17], a 40-year-old patient filled a lawsuit alleging that the total hip arthroplasty he underwent was not the appropriate procedure for his fracture around the hip joint in view of his age. The court ruled in favour of the patient, stating the total hip replacement was not indicated in the patient considering his younger age.

\section{Pre-operative Requirements and Optimization of Medical Condition}

THA, TKA are elective procedures. This warrants the patients' medical condition to be optimized before undergoing the procedure. Clelland et al. [18] found that conditions necessitating postponement or cancellation of total joint arthroplasty were present in approximately $4 \%$ of patients. Vincent et al. [19] provides comprehensive guidelines for the pre-operative risk stratification and risk reduction for joint arthroplasty. Factors which increase the rates of postoperative complications should be identified and managed prior to joint replacement. Peersman et al. [20] identified the comorbidities that were statistically significant in increasing the risk of infection were prior open surgical procedures, immunosuppressive therapy, poor nutrition, hypokalaemia, diabetes mellitus, obesity, and a history of smoking. Baek et al. [21] recommend correction of modifiable risk factors to decrease the rate of peri-prosthetic joint infection. Jamsen et al. [22] found that pre-operative reduction of glucose levels to less than $124 \mathrm{mg} / \mathrm{dL}$ decreases the rate of periprosthetic joint infection. Rasouli et al. [23] recommends a pre-operative correction of haemoglobin levels prior to joint arthroplasty. Huang et al. [24] identified malnutrition to also increase the rate of complications postoperatively. Ragni et al. [25] found that rate of postoperative infection in human immunodeficiency virus-positive haemophiliacs with CD4 counts of $200 / \mathrm{mm}^{3}$ or less appears to be high, when compared with the general population and recommends early, vigorous treatment should be instituted for suspected infection, antibiotic prophylaxis considered for invasive procedures, and surgical intervention individualised based on the balance of risks and benefits. Sendi et al. [26] recommends antimicrobial treatment of symptomatic bacteriuria, but not for asymptomatic bacteriuria prior to arthroplasty. They also found that indwelling urinary catheters are the most frequent reason for healthcare-associated urinary tract infections and should be avoided or removed as soon as possible. Thus patients should be carefully selected for arthroplasty and medical evaluation should be performed in collaboration with the internists. In the Sheuli Das vs. Dr. Kanchan Bhattacharya case (7MLCDa13; j26 January 2014) [17] the patient alleged that the orthopaedic surgeon was negligent in performing a total hip replacement when the patient's medical condition was not suitable for the procedure. The doctor successfully defended his actions by proving necessary pre-operative investigations were done, opinions of relevant specialists were obtained, and only after obtaining fitness for the procedure from all specialists was the arthroplasty performed.

The elective nature of arthroplasty also warrants the procedure to be done by an orthopaedic surgeon who is trained in arthroplasty and has sufficient experience. It is a major surgery, which should be performed in a setup which has the required infrastructure including an orthopaedic surgeon trained in arthroplasty [27]. In the RR Dobhal vs. Dr. SK Gupta case [17] the prosecution was successful in obtaining a verdict in their favour after they proved that they had requested the orthopaedic surgeon for referral to a higher medical centre for TKA but was refused. 


\section{Informed Consent}

Informed consent is meant to protect the rights of the patients and provide them with adequate information before undergoing the procedure. Its importance has risen significantly in the past few decades with it being the crux of several malpractice lawsuits. Hence, it is vital for orthopaedic surgeons to be aware of what needs to be included in the informed consent document. Improving patient education and counselling during the process of obtaining an informed consent decreases the incidence of malpractice claims [28]. For example, patient education in terms of realistic expectations after THA may be effective in reducing claims related to limb length discrepancy after THA [29]. The informed consent document should not be seen as a formality, rather given its due importance as it can often be the most vital document in defence of a malpractice lawsuit. The informed consent documentation should be comprehensive and include name, age, sex, hospital number of the patient; diagnosis; surgical procedure planned including which limb, side of body is being operated upon; the date of planned surgery; name of the chief operating surgeon; common complications of the procedure, few serious complications of the procedure; alternative treatment options with pros and cons of such alternatives; specific implants to be used; the consent for anaesthesia including type of anaesthesia and its complications; the signatures of the patient, person obtaining the consent and of the chief operating surgeon. However, it is often found that the informed consent is lacking in some of these aspects. Beresford et al. [30] reviewed the consent process of 47 THR and 53TKR patients performed by 11 different surgeons and compared the complications listed in this informed consent to those recommended by the British Orthopaedic Association (BOA). They found that in 23\% of THR and 32\% of TKR patients, none of the BOA-listed complications was documented; in $13 \%$ of THR and $15 \%$ of TKR patients, no complications were documented; in $13 \%$ of THR and $17 \%$ of TKR patients, only non-specific descriptions of complications (e.g. morbidity, mortality and medical complications) were used in their consent forms. A study involving 50 patients undergoing TKA revealed only $28 \%$ received information regarding possible complications of TKA and $85 \%$ were not given any information about the alternative treatments [31]. In another study of informed consent in THA, TKA patients, it was found that documentation of all clinically significant complications was insufficient when generic informed consent forms with blank spaces were used, hence the use of standardised procedurespecific consent forms is recommended [32].

Section 87 of the Indian Penal Code (IPC) [33] states that an "Act not intended and not known to be likely to cause death or grievous hurt, done by consent of a person above 18 years of age" is not considered an offence, while Sect. 88 of IPC [33] states that an "Act not intended to cause death, done by consent in good faith for person's benefit" is not an offence. Thus these are important IPC's that are the vital in the defence of a lawsuit filed when complications occur following an arthroplasty. The Samira Kohli case is a landmark judgement in relation to informed consent, where in its judgement the Supreme Court of India laid down guidelines for informed consent [33], stating that adequate information to be furnished by the doctor (or a member of his team) who treats the patient, should enable the patient to make a balanced judgement as to whether he should submit to the particular treatment or not. This means that the doctor should disclose: the nature and procedure of the treatment, its purpose, benefits and effects; alternatives, if any available; an outline of the substantial risk; adverse consequences of refusing treatment. But there is no need to explain remote theoretical risks involved, which may frighten or confuse a patient and result in refusal of consent for the necessary treatment.

\section{Implants}

The decision regarding which implant is to be used in the arthroplasty is one that is often made by the surgeon. This could be effected by several factors, including the surgeon's familiarity with the implant, requirement of the patient's condition, availability, and cost. For these reasons, the surgeon is often the person making the choice regarding the implant to be used. However, we must remember that ultimately the patient should have a say in what implant will be used in their body. Hence, the decision regarding implant to be used has to be shared decision after discussion between the surgeon and patient. Prokopetz et al. [34] discuss the guidelines for shared decision-making for implants in arthroplasty. They advise prior to arthroplasty, the orthopaedic surgeon discusses with the patient regarding the implant options available, the implant the surgeon feels most appropriate for the patient and the reasons for the same, the scientific evidence present regarding the implant, and also disclose any financial relationships or conflicts of interest for the surgeon. This is recommended to be a part of the informed consent obtained from the patient prior to surgery. A useful and impartial source for information regarding the various implant-specific estimates of complications and their outcomes are arthroplasty registries [35]. There are several arthroplasty registries maintained worldwide. The Mayo registry of USA is the oldest continuing registry for arthroplasty [36]. The Indian Society of Hip and Knee Surgeons (ISHKS) has established an arthroplasty registry in India and has been collecting data since 2006 [37], which can be accessed at http://www.ishks.com. It is important for 
an orthopaedic surgeon to verify the licences of an implant and manufacturer, and the outcomes of the implant is these registries prior to recommendation or use in a patient. This will be useful in the chance a lawsuit is filed in relation to the implant that was used. In the Anusuya vs. Bone and Joint Clinic case presented before the Tamil Nadu State Consumer Dispute Redressal Commission, Chennai \{first appeal No. 160/2006 [17], the implant used in total hip replacement was found to have broken. The patient alleged that this occurred due to an inferior quality implant being used. However, the verdict was in favour of the surgeon as he provided evidence that the implant used was of international quality. In the Vijaya Menon vs. BK Thampi case [17] as well the patient alleged an implant of inferior quality was used. However, the hospital produced attested copies of International Organisation of Standardization (ISO) certificate, licence for manufacturing the implant, proving the implants were nationally and internationally approved.

\section{Mixing of Components in Arthroplasty/ Mixing of Components from Different Manufacturers}

The routine practice is to use components of the same manufacturer while performing an arthroplasty. However, certain situations might arise where the surgeon wishes to use components from different manufacturers in the same joint reconstruction. Mixed THAs are defined as THAs (stem, head, and cup) comprising components made by different manufactures. This mixing of components is usually done the interest of the patient in mind. For example, a patient with THA requiring acetabular cup revision, would be subject to lesser morbidity if only the acetabular cup is replaced with an appropriate alternative, with the stem of the original manufacturer left in place if it is stable and well fit. This practice is, however, against the recommendation of all implant manufacturers. The benefit and drawbacks of performing such mixed THAs have been studied. Certain studies have reported complications from the use of components of different manufacturers $[38,39]$. However, most studies have actually found mixed THAs have similar or better outcomes and implant survival than non-mixed THAs. Tucker et al. [40] found that mixing of stems from one manufacturer with cups from another was associated with a lower revision rate. At 8 years, the cumulative percentage of revisions was $1.9 \%$ (95\% CI 1.7-2.1) in the mixed group as compared to $2.4 \%(2.3-2.5)$ in the matched group $(p=0.001)$. However, they also found that, mixing of heads from one manufacturer with stems from another was associated with a higher revision rate $(p<0.001)$. Peters et al. [41] found that 6 year revision rates for mixed THAs (3.4\% [95\% CI 3.1-3.7]) were similar to that of non-mixed THAs (3.5\% [95\% CI 3.4-3.7]). The occurrence of complications, including infection, periprosthetic fracture, dislocation, loosening of femoral component and liner wear were similar in mixed and non-mixed THAs. However, they noted that loosening of the acetabular cup was more common in mixed THAs (16 vs. 12\%). Taylor et al. [42] performed a survival analysis of 108,613 primary THAs, which showed 17-year survival of matched components and unmatched components to be similar. They also found a small, statistically significant improvement in Oxford Hip Scores for the unmatched group compared with the matched group. Thus, the mixing of components from different manufacturers may yield similar or better outcomes if it is performed when indicated as long as mixing of stem of one manufacturer with head of another manufacturer is avoided.

While the safety of mixing of components from different manufacturers may be satisfactory, the legal implications of mixing of components is another important aspect that has to be taken into consideration. Mixing of components from different manufacturers is against the guidelines of all manufacturers. This could absolve the manufacturer of complications relating to the implant use, and transfer the responsibility of manufacturer of implant to the orthopaedic surgeon. The approval from the regulatory body for the use of an implant after assessing its safety, may no longer be valid as the implant was not designed or tested for use with an implant from a different manufacturer. This opens the door for claims of medical negligence against the orthopaedic surgeon for the use of a defective and unauthorised implant. If a situation does require the use of mixed components, it is advisable to inform the patient about the need for mixed components, the benefits and drawbacks of mixing components, and to obtain an informed consent for the use of mixed components from the patient. Till date, no orthopaedic surgeon has been held legally responsible or ended up in a lawsuit for the use of mixed components, based on case law review in the United Kingdom, Germany, and the Netherlands [43]. We were unable to find any lawsuit in India pertaining to the issue of mixing of components from different manufactures for an arthroplasty. Peters et al. [43] suggests that if an orthopaedic surgeon desires to use mixed components, they are advised to avoid mixing across the fixed articulation (i.e., use a head from the same manufacturer as the stem), appropriately match sizes across the mobile articulation in hard-on-soft THAs and to avoid mixing of components in hard-on-hard bearings. In summary, despite mixing of components yielding satisfactory outcomes, it is best avoided for the risk of legal implications.

\section{Post-operative Rehabilitation Protocol}

Following a THA/TKA rehabilitation plays a vital role in the outcome of the surgery. There remain uncertainty regarding the post-operative rehabilitation and 
Table 3 Suggestions to prevent lawsuits in THA, TKA cases

Suggestions to prevent lawsuits in THA,TKA cases

Document the indication for arthroplasty clearly and ensure that the patient has realistic expectations from the surgery

Optimize medical condition prior to arthroplasty. Obtain clearance for surgery from relevant specialists if required

Obtain informed consent for surgery in all cases

Informed consent documentation should include name, age, sex, hospital number of the patient; diagnosis; surgical procedure, side of surgery; date of surgery; name of the chief operating surgeon; common complications of the procedure, few serious complications of the procedure; alternative treatment options with pros and cons of such alternatives; specific implants to be used; consent for anaesthesia and its complications; the signatures of the patient, person obtaining the consent and of the chief operating surgeon

Explain and list all common complications following THA, TKA while obtaining informed consent

For THA: nerve injury, including foot drop, limb length discrepancy, and dislocation

For TKA: incomplete pain relief/chronic pain, deep vein thrombosis/pulmonary embolism

For both: infection, bleeding, implant loosening

Only use implants from licenced manufacturers having required certifications and confirmed satisfactory results

Avoid mixing of implants from different manufacturers

Document the advice given regarding post-operative rehabilitation and mobilisation, and also if the advice is being followed by patient or not

mobilisation protocols to be followed and is often patientspecific. Early mobilisation decreases length of hospital stay and cost [44]; however, increases the chances of fall, implant breakage and is dependent on patient's pain tolerance. The length of hospital stay post arthroplasty for rehabilitation is also debatable. The usual indications for inpatient multidisciplinary rehabilitation are: two simultaneous arthroplasties, revision of a previous hip or knee arthroplasty, postsurgical complications, advanced age, comorbidities influencing the rehabilitation process, social difficulties, necessity for adaptation of the environment, insufficient or unadapted out-patient (para)medical care [45]. Surgeons and hospitals might have their own protocol regarding mobilisation and physiotherapy following arthroplasty. While this is left to the discretion of the surgeon, it is important for legal purposes that the advice given regarding mobilisation and physiotherapy be documented, as well as document whether the patient is following such advice. In the Rohini Morghade vs. Dr. AV Spare (7MLCDa118; j313-August 2014) [17], the patient developed a complication following arthroplasty. The patient was adviced by the orthopaedic surgeon for bed rest and the same was documented in the discharge summary. The fact the patient was not following this advice was used in the defence of the lawsuit by the doctor. In the Asthana vs. Sh Ramsingh Hospital Case (I(09)CPJ132) [17], an in-patient following arthroplasty who was advised bed rest, requested for a bed pan, but was refused by the hospital attendant. The patient slipped while walking and ended up fracturing her tibia and fibula. The administrative deficiency to follow post-operative rehabilitation protocol was proved and compensation was awarded. A summary of the precautions to be taken to prevent lawsuits in THA, TKA cases has been listed in Table 3 .

\section{Conclusion}

Lawsuits involving THA, TKAs are on the rise, and it is increasingly important for orthopaedic surgeons to be aware of medico-legal issues related to it. Understanding these matters, we believe will help avoid malpractice lawsuits, improve planning and protocols of orthopaedic surgeons, and help in the defence of lawsuits. Further studies on this matter should be promoted in developing countries such as India where there is deficiency of published literature on this matter.

\section{Declarations}

Conflict of interest The authors declare that they have no conflict of interest.

Ethical standard statement This article does not contain any studies with human or animal subjects performed by the any of the authors.

Informed consent For this type of study informed consent is not required.

\section{References}

1. McWilliams, A. B., Douglas, S. L., Redmond, A. C., Grainger, A. J., O'Connor, P. J., Stewart, T. D., \& Stone, M. H. (2013). Litigation after hip and knee replacement in the National Health Service. Bone Joint Journal, 95(1), 122-126. https://doi.org/10. 1302/0301-620X.95B1.30908.2.

2. McGrory, B. J., Bal, B. S., York, S., Macaulay, W., \& McConnell, D. B. (2009). Surgeon demographics and medical malpractice in adult reconstruction. Clinical Orthopaedics and 
Related Research, 467(2), 358-366. https://doi.org/10.1007/ s11999-008-0581-0.

3. Upadhyay, A., York, S., Macaulay, W., McGrory, B., Robbennolt, J., \& Bal, B. S. (2007). Medical malpractice in hip and knee arthroplasty. Journal of Arthroplasty, 22(6 Suppl 2), 2-7. https:// doi.org/10.1016/j.arth.2007.05.003.

4. Patterson, D. C., Grelsamer, R. P., Bronson, M. J., \& Moucha, C. S. (2017). Lawsuits after primary and revision total hip arthroplasties: A malpractice claims analysis. Journal of Arthroplasty, 32(10), 2958-2962. https://doi.org/10.1016/j.arth.2017.04.044.

5. Patterson, D. C., Grelsamer, R., Bronson, M. J., \& Moucha, C. S. (2017). Lawsuits After Primary And Revision Total Knee Arthroplasty: A malpractice claims analysis. Journal of American Academy of Orthopaedic Surgeons, 25(10), e235-e242. https://doi.org/ 10.5435/JAAOS-D-16-00736.

6. Bokshan, S. L., Ruttiman, R. J., DePasse, J. M., Eltorai, A. E. M., Rubin, L. E., Palumbo, M. A., \& Daniels, A. H. (2017). Reported litigation associated with primary hip and knee arthroplasty. Journal of Arthroplasty, 32(12), 3573-3577.e1. https://doi.org/ 10.1016/j.arth.2017.07.001.

7. Novi, M., Vanni, C., Parchi, P. D., Di Paolo, M., Piolanti, N., \& Scaglione, M. (2020). Claims in total hip arthroplasty: Analysis of the instigating factors, costs and possible solution. Musculoskeletal Surgery, 104(1), 43-48. https://doi.org/10.1007/ s12306-019-00590-6.

8. Kheir, M. M., Rondon, A. J., Woolsey, A., Hansen, H., Tan, T. L., \& Parvizi, J. (2018). Infection following total joint arthroplasty is the main cause of litigation: Data from one metropolitan area. Journal of Arthroplasty, 33(5), 1520-1523. https://doi.org/10. 1016/j.arth.2017.12.007.

9. Samuel, L. T., Sultan, A. A., Rabin, J. M., Surace, P. A., Yao, B., Moskal, J. T., \& Mont, M. A. (2019). Medical malpractice litigation following primary total joint arthroplasty: A comprehensive, nationwide analysis of the past decade. Journal of Arthroplasty, 34(7S), S102-S107. https://doi.org/10.1016/j.arth.2019.02.066.

10. Bhutta, M. A., Arshad, M. S., Hassan, S., \& Henderson, J. J. (2011). Trends in joint arthroplasty litigation over five years: The British experience. Annals of the Royal College of Surgeons of England, 93(6), 460-464. https://doi.org/10.1308/003588411X 587226.

11. Zengerink, I., Reijman, M., Mathijssen, N. M., Eikens-Jansen, M. P., \& Bos, P. K. (2016). Hip arthroplasty malpractice claims in the Netherlands: Closed claim study 2000-2012. Journal of Arthroplasty, 31(9), 1890-1893.e4. https://doi.org/10.1016/j.arth. 2016.02.055.

12. Gibon, E., Farman, T., \& Marmor, S. (2015). Knee arthroplasty and lawsuits: The experience in France. Knee Surgery, Sports Traumatology, Arthroscopy, 23(12), 3723-3728. https://doi.org/ 10.1007/s00167-014-3292-y.

13. Järvelin, J., Häkkinen, U., Rosenqvist, G., \& Remes, V. (2012). Factors predisposing to claims and compensations for patient injuries following total hip and knee arthroplasty. Acta Orthopaedica, 83(2), 190-196. https://doi.org/10.3109/17453674.2012.672089.

14. Chen, A., Patel, N. K., Khan, Y., Cobb, J. P., \& Gupte, C. M. (2015). The cost of adverse events from knee surgery in the United Kingdom: An in-depth review of the National Health Service Litigation Authority database. The Knee, 22(4), 286-291. https://doi. org/10.1016/j.knee.2015.04.011.

15. Gademan, M. G., Hofstede, S. N., Vliet Vlieland, T. P., Nelissen, R. G., \& Marang-van de Mheen, P. J. (2016). Indication criteria for total hip or knee arthroplasty in osteoarthritis: A state-of-thescience overview. BMC Musculoskeletal Disorders, 17(1), 463. https://doi.org/10.1186/s12891-016-1325-z.

16. Cross, W. W., 3rd., Saleh, K. J., Wilt, T. J., \& Kane, R. L. (2006). Agreement about indications for total knee arthroplasty. Clinical
Orthopaedics and Related Research, 446, 34-39. https://doi.org/ 10.1097/01.blo.0000214436.49527.5e.

17. Tiwari, S., Baldwa, M., Tiwari, M., \& Kuthe, A. (2019). Textbook on medico legal issues related to various medical specialities. (1st ed., p. 291). Jaypee Brothers 301-306.

18. Clelland, C., Worland, R. L., Jessup, D. E., \& East, D. (1996). Preoperative medical evaluation in patients having joint replacement surgery: Added benefits. Southern Medical Journal, 89(10), 958-960. https://doi.org/10.1097/00007611-199610000-00004.

19. Ng, V. Y., Lustenberger, D., Hoang, K., Urchek, R., Beal, M., Calhoun, J. H., \& Glassman, A. H. (2013). Preoperative risk stratification and risk reduction for total joint reconstruction: AAOS exhibit selection. Journal of Bone and Joint Surgery American Volume, 95(4), e191-e215. https://doi.org/10.2106/JBJS.L.00603.

20. Peersman, G., Laskin, R., Davis, J., \& Peterson, M. (2001). Infection in total knee replacement: A retrospective review of 6489 total knee replacements. Clinical Orthopaedics and Related Research, 392, 15-23.

21. Baek, S. H. (2014). Identification and preoperative optimization of risk factors to prevent periprosthetic joint infection. World Journal of Orthopedics., 5(3), 362-367. https://doi.org/10.5312/wjo.v5.i3. 362.

22. Jämsen, E., Nevalainen, P., Eskelinen, A., Huotari, K., Kalliovalkama, J., \& Moilanen, T. (2012). Obesity, diabetes, and preoperative hyperglycemia as predictors of periprosthetic joint infection: A single-center analysis of 7181 primary hip and knee replacements for osteoarthritis. Journal of Bone and Joint Surgery American Volume, 94(14), e101. https://doi.org/10.2106/JBJS.J. 01935.

23. Rasouli, M. R., Restrepo, C., Maltenfort, M. G., Purtill, J. J., \& Parvizi, J. (2014). Risk factors for surgical site infection following total joint arthroplasty. Journal of Bone and Joint Surgery American Volume, 96(18), e158. https://doi.org/10.2106/JBJS.M. 01363.

24. Huang, R., Greenky, M., Kerr, G. J., Austin, M. S., \& Parvizi, J. (2013). The effect of malnutrition on patients undergoing elective joint arthroplasty. Journal of Arthroplasty, 28(8 Suppl), 21-24. https://doi.org/10.1016/j.arth.2013.05.038.

25. Ragni, M. V., Crossett, L. S., \& Herndon, J. H. (1995). Postoperative infection following orthopaedic surgery in human immunodeficiency virus-infected haemophiliacs with CD4 counts $\leq 200 /$ $\mathrm{mm}^{3}$. Journal of Arthroplasty, 10(6), 716-721. https://doi.org/10. 1016/s0883-5403(05)80065-8.

26. Sendi, P., Borens, O., Wahl, P., Clauss, M., \& Uçkay, I. (2017). Management of asymptomatic bacteriuria, urinary catheters and symptomatic urinary tract infections in patients undergoing surgery for joint replacement: A position paper of the expert group "Infection" of swissorthopaedics. Journal of Bone and Joint Infection, 2(3), 154-159. https://doi.org/10.7150/jbji.20425.

27. Bleß, H. H. (2018). Requirements for adequate arthroplasty care (expert opinions). In: Bleß HH, Kip M, editors. White paper on joint replacement: Status of hip and knee arthroplasty care in Germany [Internet]. Springer. Chapter 6. Available from: https:// www.ncbi.nlm.nih.gov/books/NBK546139/. https://doi.org/10. 1007/978-3-662-55918-5_6.

28. Bhattacharyya, T., Yeon, H., \& Harris, M. B. (2005). The medicallegal aspects of informed consent in orthopaedic surgery. Journal of Bone and Joint Surgery American Volume, 87(11), 2395-2400. https://doi.org/10.2106/JBJS.D.02877.

29. Clark, C. R., Huddleston, H. D., Schoch, E. P., 3rd., \& Thomas, B. J. (2006). Leg-length discrepancy after total hip arthroplasty. Journal of American Academy of Orthopaedic Surgeons, 14(1), 38-45. https://doi.org/10.5435/00124635-200601000-00007.

30. Beresford-Cleary, N. J., Halliday, J., Breusch, S. J., \& Biant, L. C. (2011). Consent process for elective total hip and knee 
arthroplasty. Journal of Orthopaedic Surgery (Hong Kong), 19(3), 274-278. https://doi.org/10.1177/230949901101900302.

31. Ekmekci, P. E., Ekmekci, A. B., Karakaş, Ö., Kulduk, A., \& Arda, B. (2016). Evaluation of the informed consent procedure for total knee arthroplasty patients in Turkey. Acta Orthopaedica et Traumatologica Turcica, 50(4), 400-404. https://doi.org/10.1016/j. aott.2016.06.003.

32. Mussa, M. A., Sweed, T. A., \& Khan, A. (2014). Informed consent documentation for total hip and knee replacement using generic forms with blank spaces. Journal of Orthopaedic Surgery (Hong Kong), 22(2), 214-217. https://doi.org/10.1177/2309499014 02200220.

33. Singh, V. P. (Ed.). (2016). Legal issues in medical practice: Medicolegal guidelines for safe practice. (1st ed., pp. 55-58). Jaypee Brothers.

34. Prokopetz, J. J., Katz, J. N., Losina, E., Thornhill, T. S., Wright, J., \& Lehmann, L. S. (2013). Preceding the procedure: medical devices and shared decision making. Arthritis Care and Research (Hoboken)., 65(1), 148-151. https://doi.org/10.1002/acr.21826.

35. Hughes, R. E., Batra, A., \& Hallstrom, B. R. (2017). Arthroplasty registries around the world: Valuable sources of hip implant revision risk data. Current Reviews in Musculoskeletal Medicine, 10(2), 240-252. https://doi.org/10.1007/s12178-017-9408-5.

36. Malchau, H., Garellick, G., Berry, D., Harris, W. H., Robertson, O., Kärrlholm, J., Lewallen, D., Bragdon, C. R., Lidgren, L., \& Herberts, P. (2018). Arthroplasty implant registries over the past five decades: Development, current, and future impact. Journal of Orthopaedic Research, 36(9), 2319-2330. https://doi.org/10. 1002/jor.24014.

37. Pachore, J. A., Vaidya, S. V., Thakkar, C. J., Bhalodia, H. K., \& Wakankar, H. M. (2013). ISHKS joint registry: A preliminary report. Indian Journal of Orthopaedics., 47(5), 505-509. https:// doi.org/10.4103/0019-5413.118208.

38. Higgs, G. B., Hanzlik, J. A., MacDonald, D. W., Gilbert, J. L., Rimnac, C. M., Kurtz, S. M., \& Implant Research Center Writing Committee. (2013). Is increased modularity associated with increased fretting and corrosion damage in metal-on-metal total hip arthroplasty devices?: A retrieval study. Journal of Arthroplasty, 28(8 Suppl), 2-6. https://doi.org/10.1016/j.arth.2013.05. 040.
39. Mistry, J. B., Chughtai, M., Elmallah, R. K., Diedrich, A., Le, S., Thomas, M., \& Mont, M. A. (2016). Trunnionosis in total hip arthroplasty: A review. Journal of Orthopaedics and Traumatology, 17(1), 1-6. https://doi.org/10.1007/s10195-016-0391-1.

40. Tucker, K., Pickford, M., Newell, C., Howard, P., Hunt, L. P., \& Blom, A. W. (2015). Mixing of components from different manufacturers in total hip arthroplasty: Prevalence and comparative outcomes. Acta Orthopaedica, 86(6), 671-677. https://doi.org/ 10.3109/17453674.2015.1074483.

41. Peters, R. M., van Steenbergen, L. N., Bulstra, S. K., Zeegers, A. V., Stewart, R. E., Poolman, R. W., \& Hosman, A. H. (2016). Nationwide review of mixed and non-mixed components from different manufacturers in total hip arthroplasty. Acta Orthopaedica, 87(4), 356-362. https://doi.org/10.1080/17453674.2016.1194128.

42. Taylor, J. W., Frampton, C., \& Rothwell, A. G. (2017). Long term survival of total hip arthroplasty using implants from different manufacturers. The Journal of Arthroplasty. https://doi.org/10. 1016/j.arth.2017.09.047.

43. Peters, R. M., Hiemstra, J. T., Zijlstra, W. P., Bulstra, S. K., \& Stevens, M. (2020). To mix or not to mix? Medicolegal implications of mixed components in total hip arthroplasty. Acta Orthopaedica, 91(6), 624-626. https://doi.org/10.1080/17453674.2020.1822066.

44. Masaracchio, M., Hanney, W. J., Liu, X., Kolber, M., \& Kirker, $K$. (2017). Timing of rehabilitation on length of stay and cost in patients with hip or knee joint arthroplasty: A systematic review with meta-analysis. PLoS ONE, 12(6), e0178295. https://doi.org/ 10.1371/journal.pone.0178295.

45. Jansen, E., Brienza, S., Gierasimowicz-Fontana, A., Matos, C., Reynders-Frederix-Dobre, C., \& Hatem, S. M. (2015). Revalidation après les arthroplasties de hanche et de genou [Rehabilitation after total knee arthroplasty of hip and knee]. Revue Médicale de Bruxelles, 36(4), 313-320.

Publisher's Note Springer Nature remains neutral with regard to jurisdictional claims in published maps and institutional affiliations. 